\title{
正构烷烃分子化石与孢粉记录的指示意义对比: 以华南地区为例
}

\author{
郑艳红 ${ }^{(\mathbb{Q})}$, 周卫健 ${ }^{(*}{ }^{*}$, 谢树成 ${ }^{(3)}$,于学峰 ${ }^{(2)}$ \\ (1) 西北大学地质学系, 大陆动力学国家重点实验室, 西安 710069; \\ (2) 中国科学院地球环境研究所黄土与第四纪地质国家重点实验室, 西安 710075; \\ (3) 中国地质大学生物地质与环境地质教育部重点实验室, 武汉 430074 \\ * 联系人, E-mail: weijian@1loess.1lqg.ac.cn
}

国家自然科学基金(批准号: 40602004) 和国家重点基础研究发展计划(编号: 2004CB720200)资助项目

摘要 以我国华南地区高分辨率湖相-泥炭交互沉积序列为例, 开展正构烷烃分子化石与孢 粉记录的对比研究, 探讨和分析了它们之间的异同性及其可能原因. 结果表明, 分子化石与 孢粉不能完全对应起来, 其难以像狍粉一样能鉴别出具有不同生态意义的生物科属, 主要记 录原地植被的变化过程, 而狍粉反映的是区域性植被的平均信号. 分子化石在植被种属的明 确解释上可能要部分依赖于狍粉, 反过来分子化石也有助于提高狍粉分析中科属种的鉴定能 力. 分子化石对细节变化的敏感度要优越于狍粉, 其正构烷烃 $\mathrm{C}_{31} /\left(\mathrm{C}_{27}+\mathrm{C}_{29}+\mathrm{C}_{31}\right)$ 等指标显著地 捕捉到了 $\mathrm{H} 1, \mathrm{~B} / \mathrm{A}, \mathrm{YD}$ 事件, 以及约 9850 9585 和 8590 7920 cal a BP 两次早全新世的干凉事 件, 这些事件可与周边地区环境变化格局对应, 响应了区域环境变化和全球气候突变事件. 通过这一实例的对比研究, 说明分子化石与狍粉的相互结合, 可弥补二者之间的不足, 有效 验证和提高恢复气候、植被演化的分辨率和准确性.

关键词

华南地区

分子化石与狍粉

正构烷烃

植被与环境

对比
多气候代用指标的相互结合和印证是研究季风 气候变化模式和获取突变事件的基础. 近年来, 分子 化石已成为过去全球变化研究中极具潜力的气候代 用记录之一 $[1 \sim 6]$. 与经典的狍粉一样均为生物体不同 组织遗留下来的产物, 故所携带的信息应该不同. 可 令人遗憾的是, 在以往的诸多研究中, 多数学者均运 用二者之一解释植被及气候变化, 而有关其相互结 合的研究并不多 ${ }^{[7,8]}$. 鉴于此, 本文以我国华南地区 江西定南湖相-泥炭序列为研究载体, 在前期研究的 基础上 ${ }^{[9]}$, 通过对该区较高分辨率的正构烷烃分子 化石和狍粉相结合的分析、对比、相互检验与补充, 一方面重点探讨分子化石与孢粉在记录气候、植被变 化之间的差异及可能原因，进而评价二者的优越性;
另一方面全面地揭示末次冰盛期以来华南地区植被与 气候的演化序列, 因为现有的季风气候研究多集中于 中国中部和北部地区，华南低纬度地区具有可靠年代 的高分辨率末次冰期以来的气候与环境记录并不多.

\section{1 研究剖面概况及分析方法}

研究区位于我国华南南岭东部的九连山北翼, 粤(广东)、赣(江西)两省交界处附近, 江西省定南县县 城城南约 $2.5 \mathrm{~km}$, 地理坐标约为 $24^{\circ} 45^{\prime} \mathrm{N}, 115^{\circ} 02^{\prime} \mathrm{E}$. 该地区年均降水量约 $1592 \mathrm{~mm}$, 年平均气温约 $17.8^{\circ} \mathrm{C}$, 是长江与珠江的分水岭. 这里广泛分布花岗岩, 基底 均为不透水层, 为泥炭的发育提供了有利的条件. 泥 炭层的埋藏深度平均为 2 3 $\mathrm{m}$ 左右, 最厚处超过 $3 \mathrm{~m}$. 


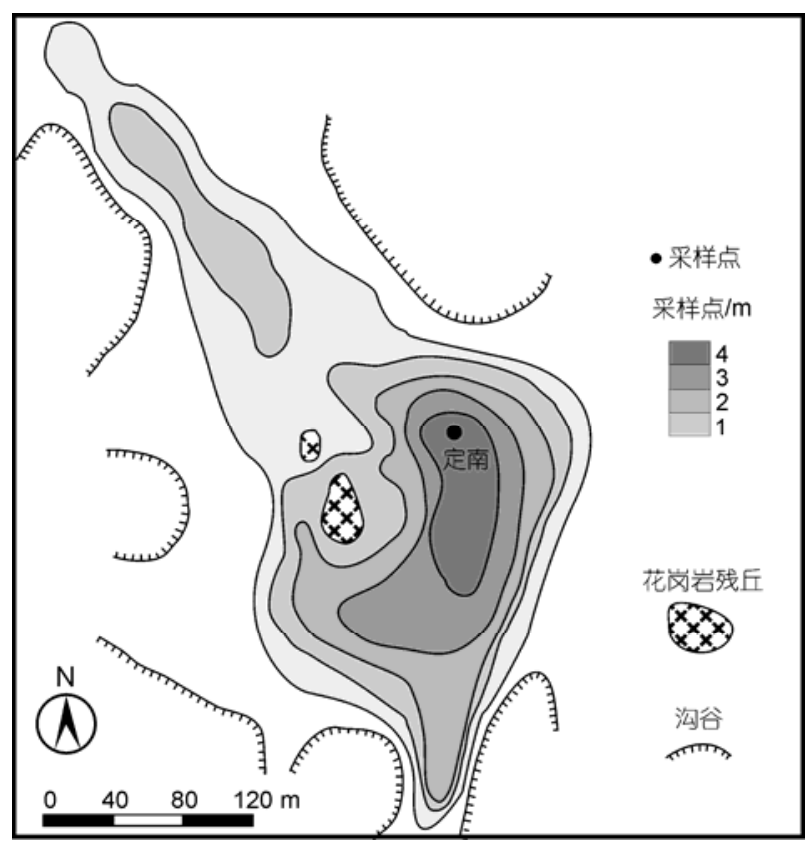

图 1 定南剖面泥炭分布

本研究的泥炭剖面埋藏于由花岗岩组成的低山丘陵 的一宽阔沟谷中, 长 $800 \mathrm{~m}$, 宽 50 500 m(图 1). 根据野外地质调查和加速器 ${ }^{14} \mathrm{C}$ 测年, 研究剖面
约在 40 115 cm(约 3800 6040 cal a BP)与 254 280 $\mathrm{cm}$ (约 14370 15630 cal a BP)堆积泥炭, 而其他时期 为湖相沉积(图 2). 我们连续采集了柱状样, 在实验 室进行 $1 \mathrm{~cm}$ 间距分样. 具体地 $\mathrm{AMS}^{14} \mathrm{C}$ 年代测年以及 孢粉分析请参阅Zhou等人 ${ }^{[10]}$.

分子化石分析首先将风干后的样品粉碎至 80 目 以下, 取 1 30 g 粉末样品, 用氯仿在超声波抽提器中 连续抽提 5 次, 每次抽提时间为 $15 \mathrm{~min}$. 将抽提液在 旋转蒸发仪上浓缩, 并用电子天平衡重后, 用层析柱 法分离出饱和烃、芳烃和非烃, 冲洗液分别为正己烷, 苯和甲醇. 饱和烃用正己烷溶解后, 直接进行气相色 谱-质谱(GC-MS)分析.

气相色谱-质谱(GC-MS)分析采用 HP6890 型气 相色谱与 HP5973 型质谱联用仪. 色谱条件: HP-5MS 石英毛细管柱 $(30 \mathrm{~m} \times 0.25 \mathrm{~mm} \times 0.25 \mu \mathrm{m})$, 始温 $70^{\circ} \mathrm{C}$, 升温速率 $3^{\circ} \mathrm{C} / \mathrm{min}$, 终温 $280^{\circ} \mathrm{C}$, 终温恒温 $20 \mathrm{~min}$, 进 样口温度 $300^{\circ} \mathrm{C}$, 进样量 $1 \mu \mathrm{L}$, 氦气为载气. 质谱条 件: 电子轰击源, 电离能量 $70 \mathrm{eV}, \mathrm{GC}$ 与 $\mathrm{MS}$ 接口温 度 $280^{\circ} \mathrm{C}$. 正构烷烃的鉴定主要依据 $\mathrm{GC} / \mathrm{MS}$ 分析的 质谱图以及标准样品, 定量依据 $\mathrm{m} / \mathrm{z} 85$ 质量色谱图 的峰面积.

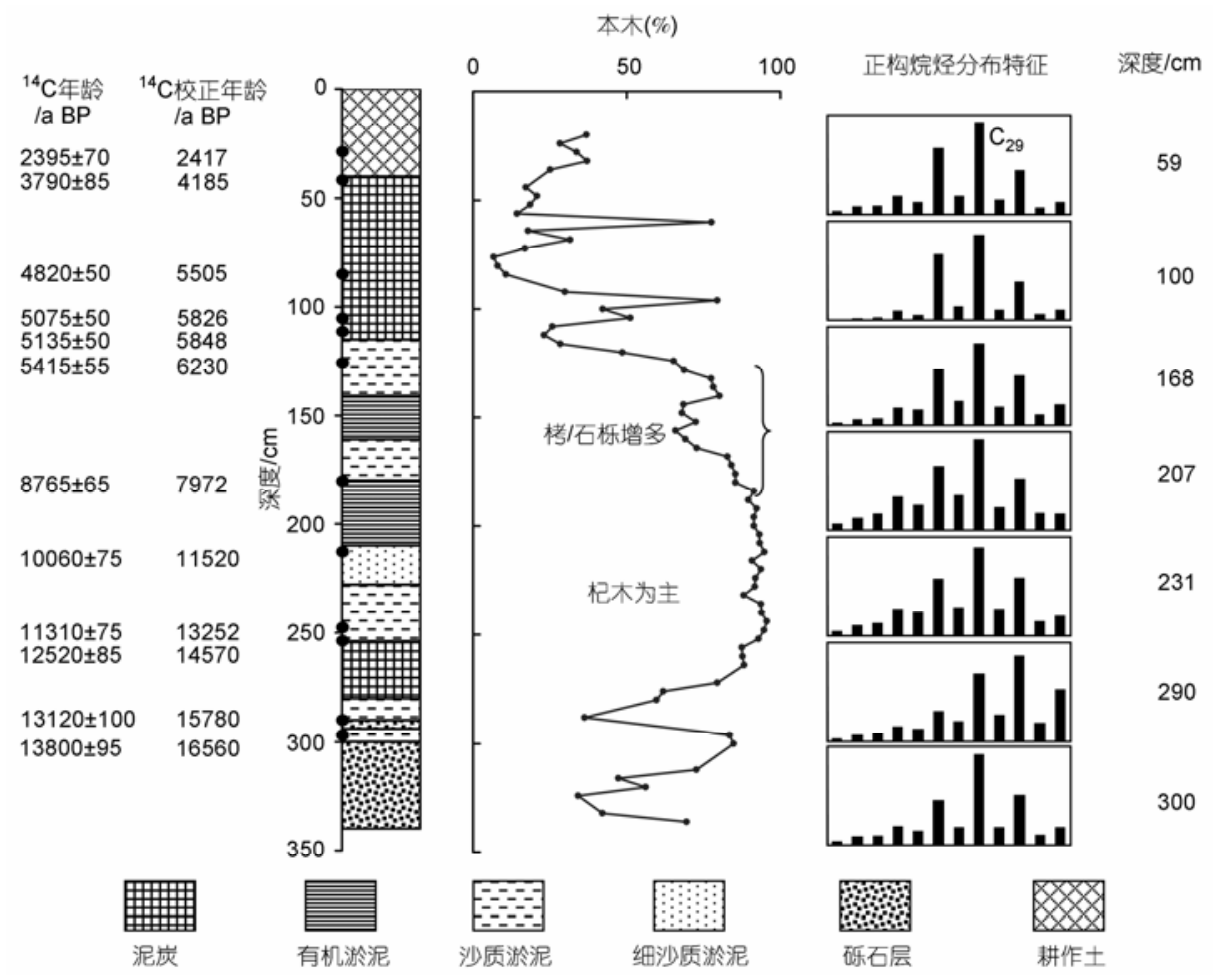

图 2

定南湖相-泥炭序列剖面地层、狍粉木本百分含量以及不同深度处沉积物中正构烷烃分布特征(横坐标为碳数, 纵坐标为相对丰度) 


\section{2 结果与讨论}

在本剖面中, 检测出种类多而丰富的类脂物分子, 这儿主要利用高碳数正构烷烃的分布和含量进行分析 与探讨, 因为这部分化合物在地质时期较为稳定 ${ }^{[11]}$, 可相对真实地反映原始的生物、气候信息. 所有样品中 检测到的正构烷烃均以高碳数为主(图 2), 即 $\mathrm{C}_{22}-\mathrm{C}_{33}$, $\mathrm{C}_{22}$ 以下含量甚微甚至缺失. 不论是泥炭还是湖相沉积 期间, 正构烷烃均以 $\mathrm{C}_{29}$ 为主峰, $\mathrm{C}_{27}$ 和 $\mathrm{C}_{31}$ 为不等的次主 峰. 这种分布特征揭示该地区沉积环境中的有机质主 要来源为高等植物, 微生物和菌藻类的输入量很少.

研究已显示, 木本植物的正构烷烃以 $\mathrm{C}_{27}$ 和 $\mathrm{C}_{29}$ 为主峰, 草本植物以 $\mathrm{C}_{31}$ 和 $\mathrm{C}_{33}$ 为主峰 ${ }^{[12]}$. 根据这一分 布特征, 可有效区别植被类型, 特别是利用这些化合 物的不同碳数之间的比值 ${ }^{[13,14]}$. 例如, Schwark等人 ${ }^{[8]}$ 用 $\mathrm{C}_{29} / \mathrm{C}_{31}$ 比值作为树木与草的贡献率重建了冰后期 至早全新世的植被变化; 张虎才等人 ${ }^{[15]}$ 利用 $\mathrm{C}_{31} /\left(\mathrm{C}_{29}+\mathrm{C}_{31}\right)$ 研究了洛川黄土剖面 $\mathrm{S} 4$ 古土壤及相邻 黄土层的植被变化. 此外, 在许多沉积物中, 运用正 构烷烃 $\mathrm{C}_{27} / \mathrm{C}_{31}$ 比值变化反映了木本植物和草本植物 相对变化的关系 ${ }^{[11,16]}$. 因此, $\mathrm{C}_{27}, \mathrm{C}_{29}$ 和 $\mathrm{C}_{31}$ 之间的比 值可以反映植被的变化过程, 从而揭示气候的演化 信息. 对于本研究, 我们经深入分析, 决定利用 $\mathrm{C}_{31} /$ $\left(\mathrm{C}_{27}+\mathrm{C}_{29}+\mathrm{C}_{31}\right)$ 和 $\left(\mathrm{C}_{27}+\mathrm{C}_{29}\right) /\left(\mathrm{C}_{27}+\mathrm{C}_{29}+\mathrm{C}_{31}\right)$ 分别代表泥 炭-湖相沉积物发育时期草本和木本植物的相对变化 (图 3 和 4), 并与孢粉结果进行对比和探讨.

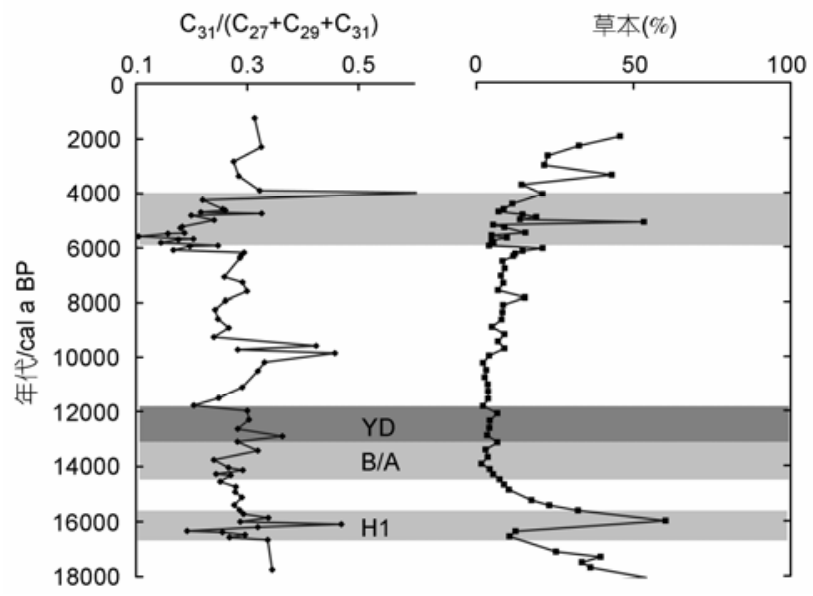

图 3 正构烷烃 $\mathrm{C}_{31} /\left(\mathrm{C}_{27}+\mathrm{C}_{29}+\mathrm{C}_{31}\right)$ 比值与孢粉草本植物 百分含量随时间的变化序列

\section{1 正构烷烃与狍粉记录的古植被对比}

在江西定南剖面中, $\left(\mathrm{C}_{27}+\mathrm{C}_{29}\right) /\left(\mathrm{C}_{27}+\mathrm{C}_{29}+\mathrm{C}_{31}\right)$ 比值

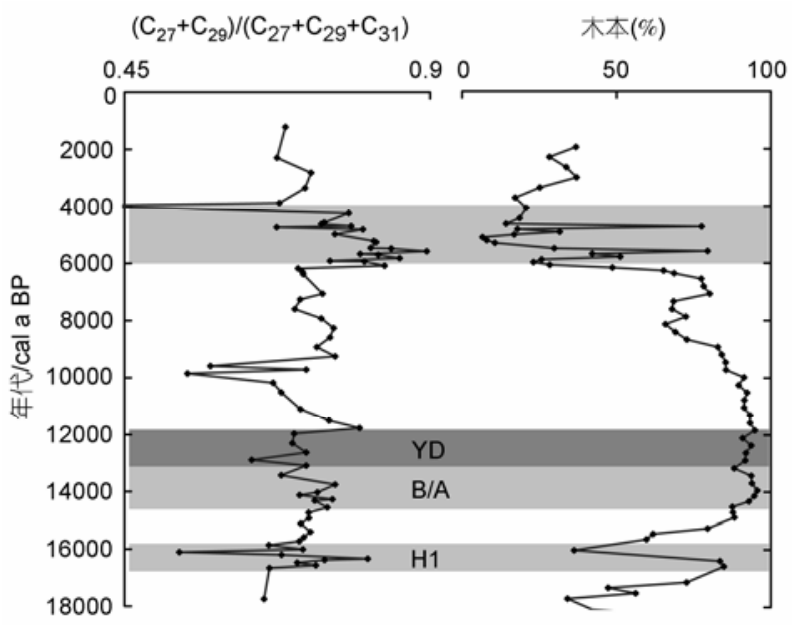

图 4 正构烷烃 $\left(\mathrm{C}_{27}+\mathrm{C}_{29}\right) /\left(\mathrm{C}_{27}+\mathrm{C}_{29}+\mathrm{C}_{31}\right)$ 比值与孢粉木本植物 百分含量随时间的变化序列

要明显高于 $\mathrm{C}_{31} /\left(\mathrm{C}_{27}+\mathrm{C}_{29}+\mathrm{C}_{31}\right)$, 说明本区主要发育木 本植物. 不论是 $\mathrm{C}_{31} /\left(\mathrm{C}_{27}+\mathrm{C}_{29}+\mathrm{C}_{31}\right)$ 反映的草本植物与 孢粉草本植物, 还是 $\left(\mathrm{C}_{27}+\mathrm{C}_{29}\right) /\left(\mathrm{C}_{27}+\mathrm{C}_{29}+\mathrm{C}_{31}\right)$ 与孢粉 木本植物对比, 均有不同之处(图 3 和 4).

在约 18000 11600 cal a BP 左右, 正构烷烃以 $\mathrm{C}_{29}$ 为主峰 (在 $290 \mathrm{~cm}$ 处以 $\mathrm{C}_{31}$ 为优势), $\left(\mathrm{C}_{27}+\mathrm{C}_{29}\right) /\left(\mathrm{C}_{27}+\right.$ $\mathrm{C}_{29}+\mathrm{C}_{31}$ ) 多大于 0.65 , 显示木本植物为主, 与孢粉记 录一致, 不同的是, 正构烷烃指标波动显著于孢粉谱 百分含量的变化. 另外, $\mathrm{C}_{31} /\left(\mathrm{C}_{27}+\mathrm{C}_{29}+\mathrm{C}_{31}\right)$ 比值可以 说在此时期是全剖面的相对高值. 例如, 在约 16101 cal a BP 左右, 该值高达 0.46 , 与草本狍粉出现一峰 值一致, 说明在湿润的杞木生长背景下(图 5), 研究 区有一个短暂的草本植被繁茂波动.

约 11600 6040 cal a BP之间的早全新世时期, $\mathrm{C}_{31} /\left(\mathrm{C}_{27}+\mathrm{C}_{29}+\mathrm{C}_{31}\right)$ 整体上低于前期, $\left(\mathrm{C}_{27}+\mathrm{C}_{29}\right) /\left(\mathrm{C}_{27}+\right.$ $\mathrm{C}_{29}+\mathrm{C}_{31}$ ) 表现出相对高值, 说明草本植物降低. 孢粉 记录中草本变化很小, 落叶阔叶杞木林在约 10000 cal a BP开始减少, 但仍然高于 30\%, 常绿阔叶林栲/

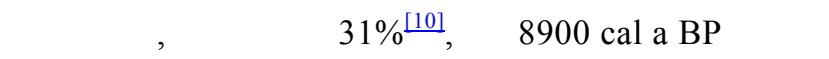
粉木本稍有下降. 然而, 令人不解的是, 在约 9850 9585 cal a BP左右, $\mathrm{C}_{31} /\left(\mathrm{C}_{27}+\mathrm{C}_{29}+\mathrm{C}_{31}\right)$ 却上升到最高, $\left(\mathrm{C}_{27}+\mathrm{C}_{29}\right) /\left(\mathrm{C}_{27}+\mathrm{C}_{29}+\mathrm{C}_{31}\right)$ 降到最低, 这一变化与孢粉 记录截然不同.

约 $6040 \sim 3800 \mathrm{cal}$ a BP 之间的中全新世, $\mathrm{C}_{31} /\left(\mathrm{C}_{27}+\mathrm{C}_{29}+\mathrm{C}_{31}\right)$ 与孢粉草本变化一致, 出现低值, 较高的 $\left(\mathrm{C}_{27}+\mathrm{C}_{29}\right) /\left(\mathrm{C}_{27}+\mathrm{C}_{29}+\mathrm{C}_{31}\right)$ 与孢粉木本表现出完 全相反的变化趋势. 虽然此时正构烷烃与孢粉草本 
植物均减少, 但孢粉降低的幅度要小于 $\mathrm{C}_{31} /\left(\mathrm{C}_{27}+\right.$ $\left.\mathrm{C}_{29}+\mathrm{C}_{31}\right)$. 因此, $\left(\mathrm{C}_{27}+\mathrm{C}_{29}\right) /\left(\mathrm{C}_{27}+\mathrm{C}_{29}+\mathrm{C}_{31}\right)$ 值的增加一 方面可能与 $\mathrm{C}_{31}$ 相对含量的减少有关, 另一方面取决 于 $\mathrm{C}_{27}$ 和 $\mathrm{C}_{29}$ 的相对丰度. $\mathrm{C}_{29} /\left(\mathrm{C}_{27}+\mathrm{C}_{29}+\mathrm{C}_{31}\right)$ 含量不低 于早全新世时期(图 5), 而 $\mathrm{C}_{27} /\left(\mathrm{C}_{27}+\mathrm{C}_{29}+\mathrm{C}_{31}\right.$ ) 比值与蕨 类植物变化趋势具有很好的对应性(图 6). 根据正构 烷烃的分布特征, 我们也发现在该层位 $\mathrm{C}_{27}$ 含量整体 上相对上升, 而此阶段发育泥炭, 乔木花粉急剧减少,
烣类植物空前繁盛, 达 $50 \%$ 以上, 草本植物整体降低. 有研究表明 [17], 蕨类孢子产生以 $\mathrm{nC}_{27}$ 为主峰的正构 烷烃. 因此, 不难推出这一时期硕类植物对 $\mathrm{C}_{27}$ 正构 烷烃的大量贡献, 使得揭示正构烷烃记录的木本植 物变化与孢粉木本形成了显著差异. 自 $3800 \mathrm{cal}$ a BP 以来, 孢粉显示出现大量禾本植物, 说明人类活动已 经开始了对植被的破坏 ${ }^{[10,18]}$, 但这一现象未能在正 构烷烃的分析结果中体现出来.

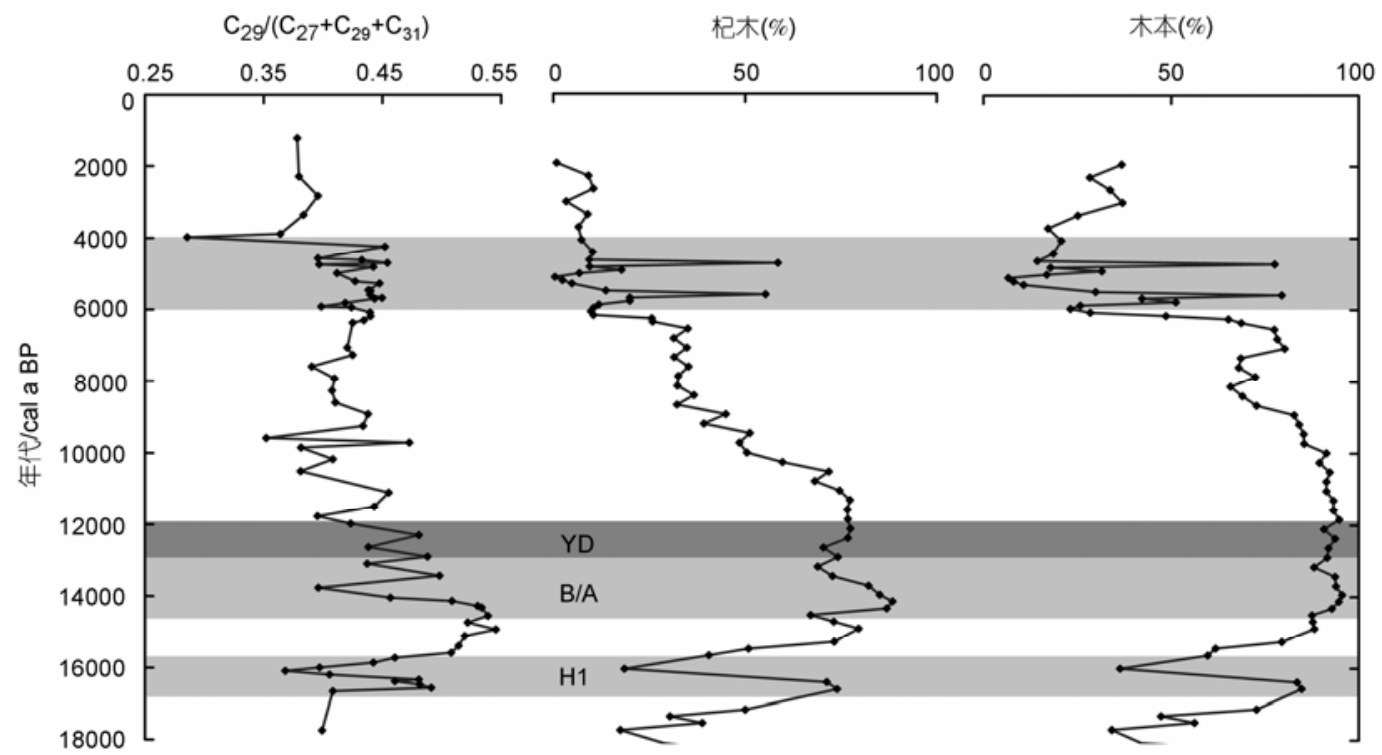

图 5 正构烷烃 $\mathrm{C}_{29} /\left(\mathrm{C}_{27}+\mathrm{C}_{29}+\mathrm{C}_{31}\right)$ 比值与狍粉杞木、木本植物百分含量随时间的变化序列

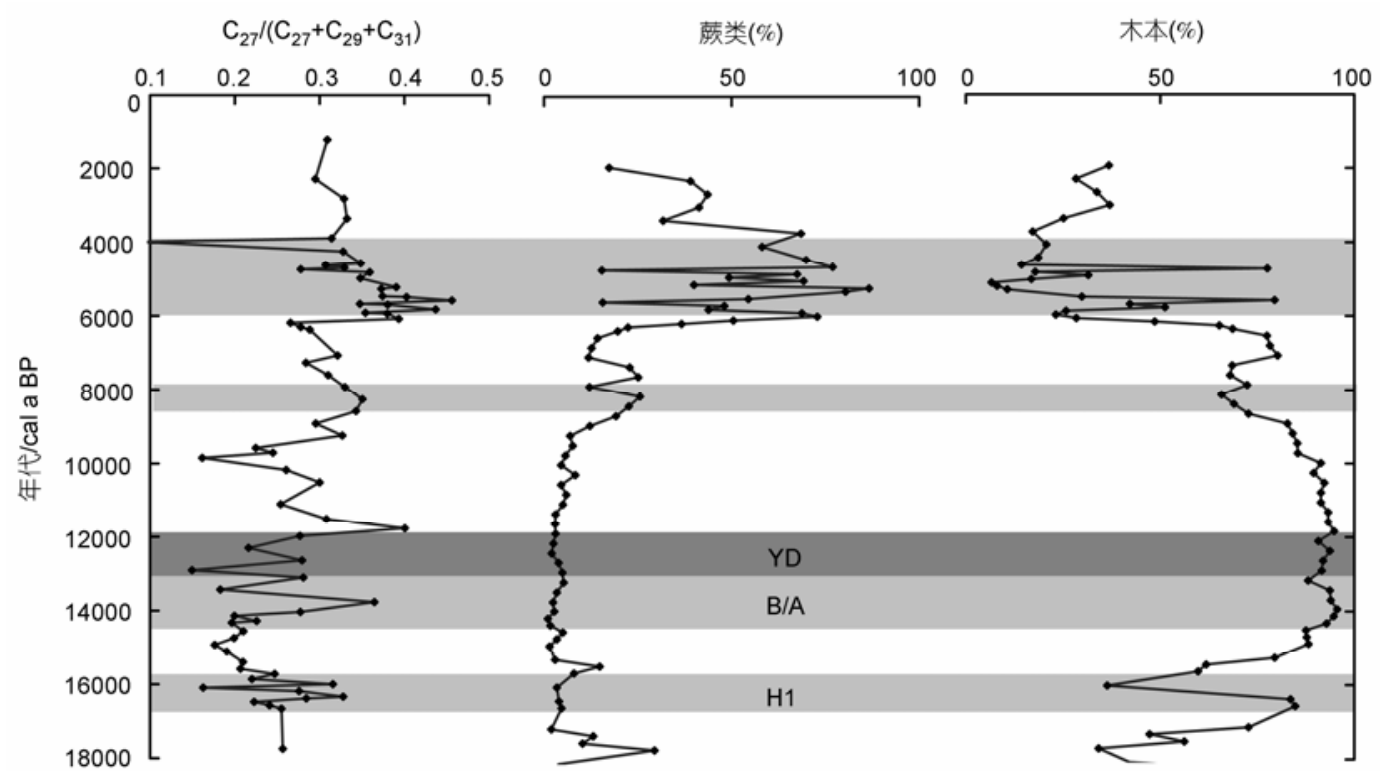

图 6 正构烷烃 $\mathrm{C}_{27} /\left(\mathrm{C}_{27}+\mathrm{C}_{29}+\mathrm{C}_{31}\right)$ 比值与矜粉蕂类、木本植物百分含量随时间的变化序列 


\section{2 正构烷烃与歌粉记录的古气候对比}

(1) 约 18000 11600 cal a BP. 在约 16570 $15630 \mathrm{cal} \mathrm{a} \mathrm{BP}$ 期间(相当于Heinrich1 事件, H1) ${ }^{[10]}$, $\mathrm{C}_{31} /\left(\mathrm{C}_{27}+\mathrm{C}_{29}+\mathrm{C}_{31}\right)$ 比值和狍粉草本均显示该时期草本 植物盖度增加, 气候偏干冷. 在博令-阿勒罗德 $(\mathrm{B} / \mathrm{A})$ 时期(约 14370 12900 cal a BP左右) ${ }^{[10]}, \mathrm{C}_{31} /\left(\mathrm{C}_{27}+\mathrm{C}_{29}+\right.$ $\left.\mathrm{C}_{31}\right)$ 和 $\left(\mathrm{C}_{27}+\mathrm{C}_{29}\right) /\left(\mathrm{C}_{27}+\mathrm{C}_{29}+\mathrm{C}_{31}\right)$ 分别稳定在 $18000 \mathrm{cal}$ $\mathrm{aBP}$ 以来的最低值和最高值, 说明草本植物自 Heinrich1 以来覆盖面积最小, 指示了相对暖而湿的 气候状况. 在新仙女木(YD)时期(约 12900 11600 cal a BP左右 $)^{[10]},\left(\mathrm{C}_{27}+\mathrm{C}_{29}\right) /\left(\mathrm{C}_{27}+\mathrm{C}_{29}+\mathrm{C}_{31}\right)$ 较前期降低, $\mathrm{C}_{31} /\left(\mathrm{C}_{27}+\mathrm{C}_{29}+\mathrm{C}_{31}\right)$ 稍有增加, 说明草本植物增加, 但 仍以森林为主, 气候相对 $\mathrm{B} / \mathrm{A}$ 时期干而凉. 与正构烷 烃相比, 该阶段孢粉组合的百分含量(草本和木本)除 了 $\mathrm{H} 1$ 外, 在 $\mathrm{B} / \mathrm{A}$ 和YD时期变化均很小.

(2) 约 11600 6040 cal a BP. 初期, $\mathrm{C}_{31} /\left(\mathrm{C}_{27}+\right.$ $\mathrm{C}_{29}+\mathrm{C}_{31}$ )增加, $\left(\mathrm{C}_{27}+\mathrm{C}_{29}\right) /\left(\mathrm{C}_{27}+\mathrm{C}_{29}+\mathrm{C}_{31}\right)$ 降低, 孢粉基 本稳定变化. 值得一提的是, 在约 9850 9585 cal a BP, $\mathrm{C}_{31} /\left(\mathrm{C}_{27}+\mathrm{C}_{29}+\mathrm{C}_{31}\right)$ 上升到最高, $\left(\mathrm{C}_{27}+\mathrm{C}_{29}\right) /\left(\mathrm{C}_{27}+\mathrm{C}_{29}+\mathrm{C}_{31}\right)$ 降到最低, 说明在总体温暖湿润的全新世适宜期背 景下出现了相对干旱的气候环境, 这在孢粉记录中 尚无留有印记(图 3 6). 这一事件的发现并非偶然. 在中国北方, 内蒙古中东部太仆寺全新世的植硅体 和狍粉记录表明, 10000 8720 a BP羊草-大针茅草原 中蓝刺头类植物, 蒿属及藜科植物较多, 与冬季风较 强有关 ${ }^{[19]}$. 新疆诸多湖泊如乌伦古湖 ${ }^{[20]}$ 、艾比湖 ${ }^{[21]}$ 、 玛纳斯湖 ${ }^{[22]}$ 以及蒙古的湖谷地区 ${ }^{[23]}$ 均表现为温凉干 燥和低湖面特征. 大约与此同时, 在青海湖地区全新 世早期向全新世中早期转换期间气候明显转冷 [24], 这在北大西洋深海沉积 ${ }^{[25]}$ 和青藏高原的古里雅冰芯 [26]均有记录.

另外, 值得注意的是, 在约 8590 7920 cal a BP 左右, $\mathrm{C}_{27} /\left(\mathrm{C}_{27}+\mathrm{C}_{29}+\mathrm{C}_{31}\right)$ 有一小峰值, 孢粉木本从约 $80 \%$ 降到 $65 \%$, 䓲类植物从 $10 \%$ 以下增加到 $25 \%$ 左右, 这也在 $\mathrm{C}_{29} /\left(\mathrm{C}_{27}+\mathrm{C}_{29}+\mathrm{C}_{31}\right)$ 指标中表现出来, 两种生物 记录均指示气候可能发生突变. 青藏高原中部全新 世气候变化的湖泊沉积地球化学记录表明, 在约 8600 8400 cal a BP发生强烈冷事件 [27]. 姚檀栋等人 ${ }^{[28]}$ 对敦德冰芯研究中曾发现在 $8.7 \mathrm{ka} \mathrm{BP}$ 有一次强烈 降温事件, 古里雅冰芯记录 $8.2 \mathrm{ka} \mathrm{BP}$ 有一次冷事件 [26]. 贵州董歌石笋同位素指标, 表明在 7.2, 8.3 ka BP 有亚洲季风减弱事件 [29]. 因此, 该研究区的
7920 8590 cal a BP期间的突发事件，持续时间较长， 很可能对应于全球 $8.2 \mathrm{cal} \mathrm{ka} \mathrm{BP}$ 的冷事件 ${ }^{[30]}$, 显然表 现的幅度不如中国北方地区显著.

(3) 约 6040cal a BP以来. 约 6040 3800 cal a $\mathrm{BP}$ 左右发育富营养泥炭, 木本和草本植物降低, 䓲类 植物空前繁盛, $\mathrm{C}_{31} /\left(\mathrm{C}_{27}+\mathrm{C}_{29}+\mathrm{C}_{31}\right)$ 比值降低, $\mathrm{C}_{27} /\left(\mathrm{C}_{27}+\right.$ $\mathrm{C}_{29}+\mathrm{C}_{31}$ )值增加, 均指示气候干凉. 自 $3800 \mathrm{cal} \mathrm{a} \mathrm{BP}$ 以来, $\mathrm{C}_{31} /\left(\mathrm{C}_{27}+\mathrm{C}_{29}+\mathrm{C}_{31}\right)$ 上升, 而 $\left(\mathrm{C}_{27}+\mathrm{C}_{29}\right) /\left(\mathrm{C}_{27}+\mathrm{C}_{29}+\mathrm{C}_{31}\right)$ 降低, 表明温度下降的同时, 湿度也相对降低. 孢粉 显示出在自然环境变化的基础上, 叠加有人类活动 的影响 $[9,10,18]$.

\section{3 正构烷烃分子化石与狍粉记录差异的可能原因}

由上分析可知, 正构烷烃与孢粉之间在揭示气 候、植被变化过程方面既有共性, 又有差异性. 结合 图 2 也不难得出, 整个时期狍粉组合类型发生了很大 变化, 而在正构烷烃中, 主要以 $\mathrm{C}_{29}$ 为主峰, 亦即主 峰化合物几乎没变; 或者孢粉组合分布基本类似, 正 构烷烃 $\mathrm{C}_{27} \sim \mathrm{C}_{31}$ 的相对含量或比值却发生了变化(图 2 6). 例如, 在约 128 184 cm 之间, 常绿阔叶林栲/ 石栎增多，高达 31\%，杞木多在 31\% 36\%之间变化; 在 272 185 cm 之间, 杞木多高达 70\%以上, 而栲/石 栎却不到 $10 \%$, 可是正构烷烃的主峰化合物并无改 变(图 2).

孢粉属种的确定主要是基于形态学研究, 是形 态种; 分子化石主要基于其化学成分, 是化学种(或 分子种), 这两种类型的种不完全相同. 例如, 在末次 冰消期(B/A和YD)以及约 9850 9585 cal a BP左右, 正构烷烃与孢粉分析结果明显不同. 如果说这些时 期植被尚无演替, 那则是气候的变化引起了正构烷 烃相对含量的变化, 而这种气候变化的幅度微小, 并 未引起当时研究区生态系统的更替. 在现代生物学 中就有很多形态种不变而化学成分发生变化的例子, 已经证实某些分子种在反映环境条件变化上比形态 种更加灵敏 ${ }^{[31,32]}$. 另一方面, 我们知道狍粉一般只能 鉴定到属而不能鉴定到种，可能是某些植物种发生 了变化, 使得源于这些种的分子化石(正构烷烃)发生 了相应地变化, 这在狍粉中未能体现出来.

再者, 正构烷烃是生物有机体遗留下来的痕迹, 难以像狍粉一样可与特定的生物科属等直接联系起来, 但是容易保存、且稳定; 而孢粉, 在一些地层中保存不 理想，且易被风、水流等远距离搬运，通常反映了区域 性植被的变化过程. 还有, 狍粉的搬运问题和一些树 
种花粉的强传播能力及其超代表性，也有可能掩盖了 植被环境变化的真实信息. 例如, 本区的主要木本植 物是杞木占优势, 但有研究表明杞木花粉属超代表性 花粉 ${ }^{[33]}$, 因而可能会在某种程度上造成植被、环境的 偏离, 故孢粉指标的单独运用应慎重. 相比而言, 分 子化石则主要来自植物残体, 孢粉比植物碎屑和残体 更易被搬运，这种植物残体中的有机组分及其分子标 志物主要反映局部或当地的植被变化, 记录了沉积局 部(如植物附近)或原地的植物碎屑(如叶子)的组成,
这与Farrimond等人 ${ }^{[7]}$ 的研究相符. 另外, 即使植物残 体的物理结构受到破坏, 但保存于其中的有机化合物 的分子结构或基本碳骨架仍然可以在特定的条件下保 存下来, 并通过先进的仪器检测出来. 此外, 在这种 湖沼相沉积环境中, 正构烷烃除了记录陆生植物的信 息外, 还可能记录水生植物; 而孢粉可能主要记载了 陆生植物的贡献量. 因此，如果将分子化石正构烷烃 与狍粉记录结合起来, 二者相互弥补、验证, 可提高气 候、植被获取的分辨率和精确度.

致谢 审稿专家对本文提出建设性意见, 中国地质大学(武汉)生物地质与环境地质教育部重点实验室(GC/MS 实验室) 对实验工作给予了极大支持, 在此一并表示感谢.

\section{参考文献}

1 Brassell SC, Eglinton G, Marlowe I T, et al. Molecular stratigraphy: A new tool for climatic assessment. Nature, 1986, 320: 129-133

2 Prahl F G, Wakeham S G. Calibration of unsaturation patterns in long-chain ketone compositions for palzeotemperature assessment. Nature, 1987, 330: 367-369[D O I]

3 Huang Y S, Street-Perrott F A, Perrott R A, et al. Glacial-interglacial environmental changes inferred from molecular and compound - specific $\delta^{13} \mathrm{C}$ analyses of sediments from Sacred Lake, Mt. Kenya. Geochim Cosmochim Acta, 1999, 63: 1383-1404[D OI]

4 Z heng Y H, Z hou W J, Meyers P A, et al. Lipid biomarkers in the Z oigê Hongyuan peat deposit: Indicators of Holocene climate changes in West China. Org G eochem, 2007, 38: 1927-1940[D OI]

5 Xie S C, Nott C J, Avsejs L A, et al. Molecular and isotopic stratigraphy in an ombrotrophic mire for paleoclimate reconstruction. Geochim Cosmochim Acta, 2004, 68: 2849-2862[D O I]

6 郑艳红, 周卫健, 谢树成. 若尔盖高原全新世气候序列的类脂分子化石记录. 第四纪研究, 2007, 27: 108-113

7 Farrimond P, Flanagan R L. Lipid stratigraphy of a Flandrian peat bed (Northumberland, UK): Comparison with the pollen record. Holocene, 1996, 6: 69-74[D OI]

8 Schwark L, Z ink K, Lechterbeck L. Reconstruction of postglacial to early H olocene vegetation history in terrestrial Central Europe via cuticular lipid biomarkers and pollen records from lake sediments. G eology, 2002, 30: 463 - 466[D O I]

9 Z hou W J, Xie S, Meyers P A, et al. Reconstruction of late glacial and Holocene climate evolution in southern China from geolipids and pollen in the Dingnan peat sequence. O rg Geochem, 2005, 36: 1272-1284[D O I]

10 Zhou W J, YuX F, Jull A J T, et al. High-resolution evidence from southern China of an early Holocene optimum and a mid-H olocene dry event during the past 18000 years. Q uat Res, 2004, 62: 39-48[D O I]

11 Meyers P A, I shiwatari R. Lacustrine organic geochemistry: An overview of indicators of organic matter sources and diagenesis in lake sediments. Org Geochem, 1993, 20: 867-900[D O I]

12 Cranwell P A, Eblinton G, Robinson N. Lipids of aquatic organisms as potential contributors to lacustrine sediments. Org G eochem, 1987, 11: 513-527[D OI]

13 Z hang Z H, Z hao M X, Eglinton G, et al. Leaf wax lipids as paleovegetational and paleoenvironmental proxies for the Chinese Loess Plateau over the last 170 kyr. Q uat Sci Rev, 2006, 25: 575-594[D O I]

14 Schefuss E, Ratmeyer V, Stuut J B W, et al. Carbon isotope analysis of $n$-alkanes in dust from the lower atmosphere over the central eastern A tlantic. Geochem Cosmochim Acta, 2003, 67: 1757-1767[D O I]

15 张虎才, 杨明生, 张文翔, 等. 洛川黄土剖面 S4古土壤及相邻黄土层分子化石与植被变化. 中国科学 D 辑: 地球科学, 2007, 37: $1634-1642$

16 谢树成, 易轶, 刘育燕, 等. 中国南方更新世网文红土对全球气候变化的响应: 分子化石记录. 中国科学 D 辑: 地球科学, 2003, 33: 411-417

17 张惠之, 盛国英, 王开发, 等. 孢粉生烃热模拟试验研究——I：锁类孢子烷烃组分生物标志物分布. 沉积学报, 1996, 14(增 刊): 107-114

18 萧家仪, 吕海波, 周卫健, 等. 末次盛冰期以来江西大湖狍粉植被与环境演变. 中国科学 D 辑: 地球科学, 2007, 37: 789-797 
19 黄翡, K Lisa, 熊尚发, 等. 内蒙古中东部全新世草原植被、环境及人类活动. 中国科学 D 辑: 地球科学, 2004, 34: 1029-1040

20 蒋庆丰, 沈吉, 刘兴起, 等. 西风区全新世以来湖泊沉积记录的高分辨率古气候演化. 科学通报, 2007, 52: 1042-1049

21 吴敬禄, 沈吉, 王苏民, 等. 新疆艾比湖地区湖泊沉积记录的早全新世气候环境特征. 中国科学 D 辑: 地球科学, 2003, 33: 569-575

22 Rhodes T E, Gasse F, Lin R F, et al. A Late Pleistocene Holocene lacustrine record from Lake Manas, Z unggar (northern Xinjiang,western China). Palaeogeogr Palaeoclimatol Palaeoecol, 1996, 120: 105-121[D O I]

23 Komatsu G, Brantingham P J, O Isen J W, et al. Pal eoshoreline geomorphology of Boon T sagaan N uur, T sagaan N uur and O rog N uur: The valley of lakes, Mongolia. Geomorphology, 2001, 39: 83-98[D O I]

24 沈吉, 刘兴起, Matsumoto R. 晚冰期以来青海湖沉积物多指标高分辨率的古气候演化. 中国科学 D 辑: 地球科学, 2004, 34: $582-589$

25 Bond G, Heinrich H, Broecker W S, et al. Evidence for massive discharges of icebergs into N orth Atlantic ocean during the last gla cial period. Nature, 1992, 360: 245-249[D OI]

26 王宁练, 姚檀栋, Thompson L G, 等. 全新世早期强降温事件的古里雅冰芯记录证据. 科学通报, 2002, 47: 818 -823

27 吴艳宏, Andreas L, Bernd W, 等. 青藏高原中部全新世气候变化的湖泊沉积地球化学记录. 中国科学 D 辑: 地球科学, 2007, 37: 1185-1191

28 姚檀栋, 施雅风, Thompson L G, 等. 祁连山敦德冰心纪录的全新世气候变化. 见: 中国全新世大暖期气候与环境. 北京: 海 洋出版社, 1992. 206-211

29 Wang $\mathrm{Y} \mathrm{J}$, Cheng $\mathrm{H}$, Lawrence $\mathrm{E}$ dwards R, et al. The Holocene A sian monsoon: links to solar changes and $\mathrm{N}$ orth A tlantic climate. Science, 2005, 308: 854-857[D O I]

30 Bond G, Showers W, Cheseby M, et al. A pervasive millennial-scale cycle in north Atlantic Holocene and glacial climates. Science, 1997, 278: 1257-1266[D OI]

31 Barber K E. Peat Stratigraphy and Climatic Change: A Palaeoecological Test of the Theory of Cyclic Peat Bog Regeneration. Balkema: Kotterdam, 1981. 175-185

32 谢树成, Evershed R P. 泥炭分子化石记录的气候变迁和生物演替的信息. 科学通报, 2001, 46: 863-866

33 Bradlley R S. Q uatemary Paleoclamatology. Boston: Allen \& O nwin, 1985. 295 